\title{
Determination of the Root Causes for Cracking in a Large-Size Cast Ingot of AISI 4317 Steel Using Microstructural Analysis
}

\author{
Abdelhalim Loucif ${ }^{1} \cdot$ Matthieu Bitterlin ${ }^{1} \cdot$ Mohammad Jahazi $^{1} \cdot$ Rami Tremblay $^{2} \cdot$ Jean-Benoît Morin $^{2}$ • \\ Louis-Philippe Lapierre-Boire ${ }^{2}$
}

Received: 4 January 2018 / Accepted: 21 February 2018/ Published online: 6 March 2018

(C) Springer Science+Business Media, LLC, part of Springer Nature and ASM International 2018

\begin{abstract}
The objective of the present work is to study the root causes for the cracking and material detachment from the external surface of a 10 metric tons high-strength low-alloy steel ingot after solidification and annealing processes. Failure analysis investigations were conducted on different samples from the cracked areas as well as from non-cracked ones. A combination of optical and electron microscopies, x-ray diffraction, and microhardness techniques were used to study and analyze the nature, morphology, and composition of the different microstructural components in the cracked regions. Thermodynamic software, Thermo-Calc ${ }^{\circledR}$ was used to corroborate and interpret the experimental findings with the existing theories. The results indicated a strong intergranular character of the cracks accompanied by the presence of second-phase particles at prior austenite grain boundaries. Segregation of chromium and manganese was demonstrated through local chemical analysis of the grain boundaries. It was concluded that a rapid cooling rate combined with the weakening of grain boundaries was at the origin of crack initiation.
\end{abstract}

Keywords Cast ingot cracking $\cdot$ High-strength steel $\cdot$ Grain boundaries $\cdot$ Cooling rate $\cdot$ Carbides $\cdot$ Segregation

\section{Introduction}

High-strength steels used for critical applications in energy and transportation industries have very-high-quality requirements. Obtaining high-quality steel products requires suitable properties with a minimum level of defects. For example, for critical applications such as turbine shafts, the material must be free of any microcrack- or crack-sensitized microstructural conditions. Therefore, the occurrence of such defects during the manufacturing process must be avoided, as it will result in additional inspection steps, repairs, or even scrapping of the entire ingot. For large-size steel ingots, it has been reported that cracking may appear during casting [1], forging [2], and/or

Abdelhalim Loucif

abdelhalim.loucif.01@gmail.com

1 Département de Génie Mécanique, École de technologie supérieure, 1100, Rue Notre-Dame Ouest, Montréal, QC H3C 1K3, Canada

2 Finkl Steel-Sorel, 100 McCarthy, Saint-Joseph-de-Sorel, QC J3R 3M8, Canada heat treatment [3] operations. Among the above steps, casting is the most important one due to the complex heat and mass transfer phenomena that occur during solidification which result in shrinkage, micro(macro)segregation, phase transformations, generation of significant local stresses, etc., and may lead to cracking upon solidification. The sensitization of the microstructure after solidification could be the source of cracking during subsequent forging and quench and temper operations.

Due to both technical and economical importance of the topic, many researches have been devoted, in recent years, to understand the root causes of this phenomenon. Depending on the location, size, and morphology of the crack, three major sources and mechanisms have been proposed:

1. Precipitation of secondary phases such as sulfides $[4,5]$, aluminum nitrides [6], or phosphorus segregation [7]. Generally, these phases are observed at the grain boundary regions and result from the segregation of alloying elements.

2. Hot cracking (or hot tearing) is another important mechanism in inducing cracking in castings [8]. In this 
case, cracks initiate by the voids created because of the combined effects of solidification shrinkage and incomplete liquid feeding from the mushy zone.

3. Thermal stresses developed during solidification and cooling of the ingot could also be at the origin of crack formation $[2,9,10]$.

The large number of material and process parameters during casting of large-size ingots considerably influences the susceptibility to crack initiation of high-strength steels and the identification of the cracking mechanisms, and hence, minimizing or avoiding their occurrence presents many challenges [8]. In the present work, a comprehensive study on cracking in large-size castings of a medium-carbon high-strength steel AISI 4317 (17CrNiMo6) used for turbine shaft applications has been carried out. The root causes and possible cracking mechanisms are discussed with the view to propose solutions for avoiding the occurrence of such defects. To this end, cracks in different locations and with different sizes were systematically characterized and analyzed using a combination of techniques such as x-ray diffraction, microhardness, optical and electron microscopies, and chemical mapping to examine the samples and interpret the results.

\section{Experimental Procedure}

The detached block (Fig. 1) was obtained from a 10 metric tons (MT) fractured cast ingot of a medium-carbon highstrength steel. The ingot had $86 \mathrm{~cm}$ diameter and $320 \mathrm{~cm}$ length. The material for the study was provided by Finkl Steel-Sorel, Quebec, Canada, and its nominal chemical composition is given in Table 1. The casting was performed using bottom pouring in a cylindrical cast-iron mold at a temperature around $1570{ }^{\circ} \mathrm{C}$. In this work, the crack examinations were carried out on the detached block from the external surface of the ingot after solidification and annealing steps. For sample preparation purposes, the

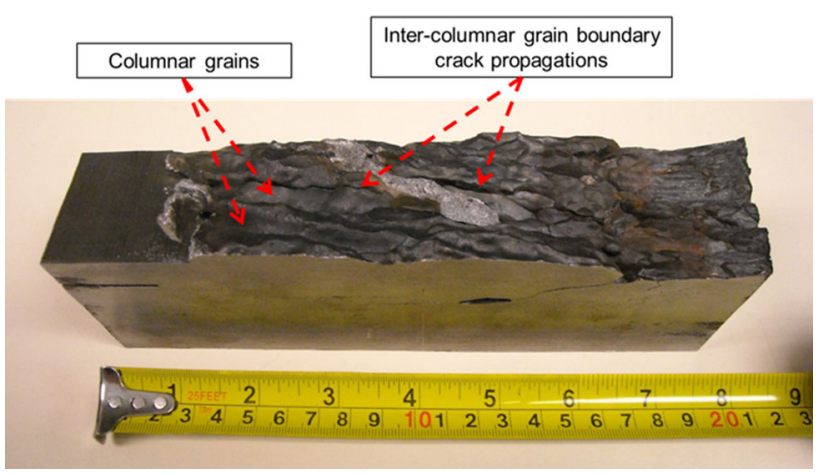

Fig. 1 Fracture morphology of the detached block from the external surface of 10 MT high-strength steel ingot detached block was initially machined from both sides. Then, it was cut in five smaller blocks, as shown in Fig. 2a. Finally, several samples, with the dimensions of $10 \times 15 \times 15 \mathrm{~mm}^{3}$, were collected from the upper parts of these small blocks (Fig. 2b). For microstructural characterizations, after mounting, samples were polished with SiC paper from 240 to 1200 grade, finished with $1-\mu \mathrm{m}$ diamond grain paste and etched with $3 \%$ Nital solution. For optical microscopy observations, an Olympus LEXT OLS4100 laser confocal microscope was used. For scanning electron microscopy (EDS) characterizations, a Hitachi SU-82 Cold Field Emission Gun, at $15 \mathrm{kV}$ equipped with energy-dispersive spectroscopy (EDS) capability, was employed. Phase identifications were carried out using an X'Pert3 MRD PANalytical x-ray diffractometer with $\mathrm{CuK} \alpha$ radiation, with a step size of $0.0668451^{\circ}$ of $2 \theta$, complemented with Vickers microhardness, according to the ASTM standard [11], with a load application of $50 \mathrm{~g}$. Finally, Thermo-Calc ${ }^{\circledR}$ thermodynamic software was used to predict the nature of phases that could be formed in the temperature range $25-1600{ }^{\circ} \mathrm{C}$.

\section{Results}

The observation of the fracture surface of the detached block (Fig. 1) revealed grains with elongated morphology over the entire fractured zone. These elongated grains probably belong to the columnar zone in the cast ingot [12]. The microscopic examination also revealed that crack propagation follows the columnar grain boundaries, which is the sign of an intercolumnar grain boundary character. Also, analysis of the cut surface of the small block number 4 , as shown in Fig. 2b, revealed that the cracks propagate inside the detached block until a certain depth which is indicative of the occurrence of internal crack propagation. On the other hand, Fig. 3 presents the optical micrograph of a sample taken from the small block number 3 (Fig. 2a). In this case, it can be seen that the upper part of this sample was detached and the cracks are very visible and seem to follow the grain boundaries. The analysis of the microstructure shown in Fig. 3 revealed the presence of two phases, a white color phase and a contrasted darker one. It also revealed a dendritic morphology of white phase in some regions of grain boundaries. These findings are in agreement with previous results on the AISI 4317 [14]. Vickers microhardness measurements showed that the white phase presents a microhardness of $177 \pm 15 \mathrm{HV}$, whereas the hardness of the more contrasted phase is in the range $350 \pm 24 \mathrm{HV}$ value. The white ductile phase is present in small proportions distributed homogeneously on the surface of the simple. However, this zone seems to be more concentrated close to grain boundaries and therefore 
Table 1 Nominal chemical composition of AISI 4317 (wt.\%)

\begin{tabular}{lllllllllllll}
\hline $\mathrm{C}$ & $\mathrm{Mn}$ & $\mathrm{Ni}$ & $\mathrm{Cr}$ & $\mathrm{Mo}$ & $\mathrm{Si}$ & $\mathrm{Cu}$ & $\mathrm{P}$ & $\mathrm{S}$ & $\mathrm{V}$ & $\mathrm{Al}$ & $\mathrm{N}$ & $\mathrm{Fe}$ \\
\hline 0.17 & 0.57 & 1.52 & 1.86 & 0.35 & 0.40 & 0.15 & 0.009 & 0.005 & 0.033 & 0.025 & 0.0071 & Balance \\
\hline
\end{tabular}

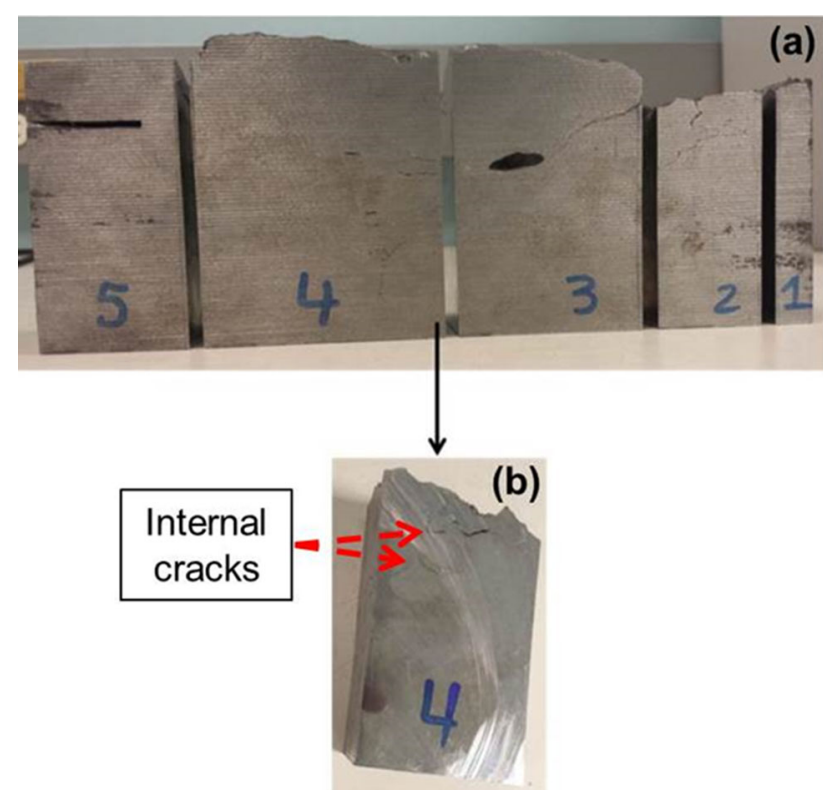

Fig. 2 Sample preparation: (a) cutting of the detached block and (b) revelation of the presence of internal crack

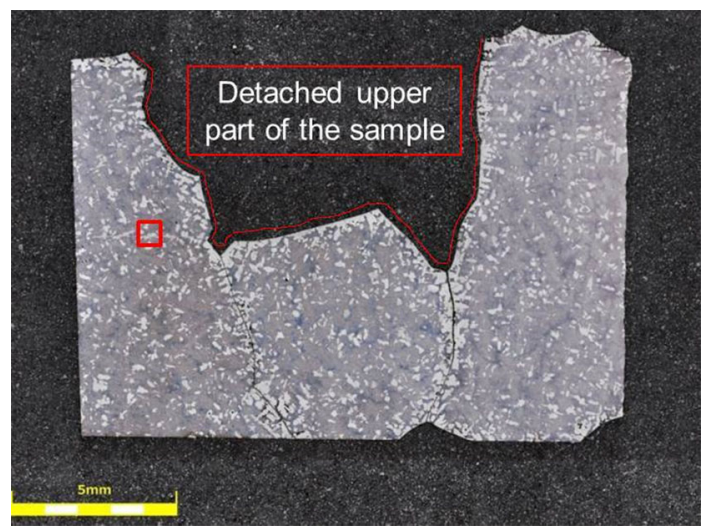

Fig. 3 Optical micrograph showing the intergranular character of the crack and presence of pro-eutectoid ferrite phase (white phase)

the intergranular cracks. Examination of the cracked zone at higher magnification, as shown in Fig. 4, confirmed that the white phase is not totally continuous around the cracks.

Figure 5 presents a zoom of the region marked by a square in Fig. 3. In addition to the two distinct observed phases, a third phase in the form of precipitates is observed within the white phase and at its boundaries. ThermoCalc $^{\circledR}$ simulation presented in Fig. 6 shows the different phases that could be formed in the investigated steel in the temperature range $25-1600{ }^{\circ} \mathrm{C}$. In addition to ferrite, austenite, and liquid phases (Fig. 6a), other secondary

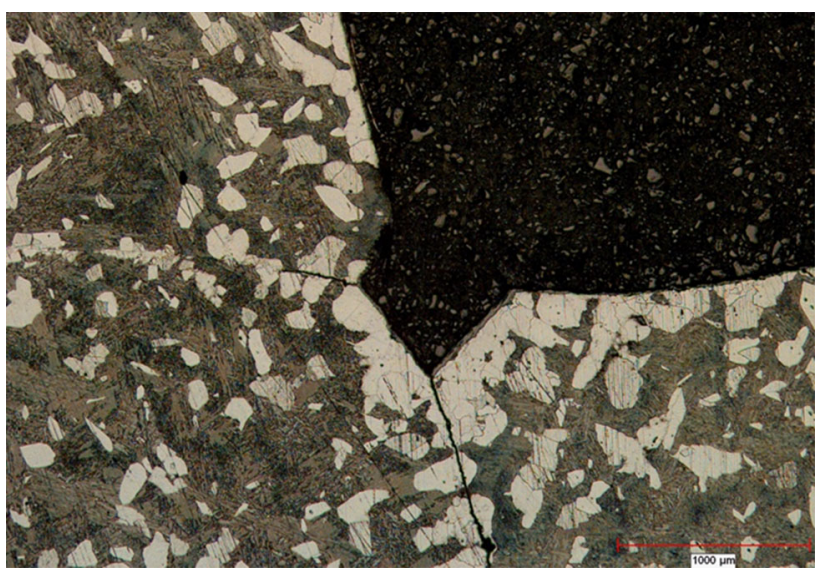

Fig. 4 Optical micrograph showing the discontinuity of pro-eutectoid ferrite phase (white phase) around the intergranular cracks

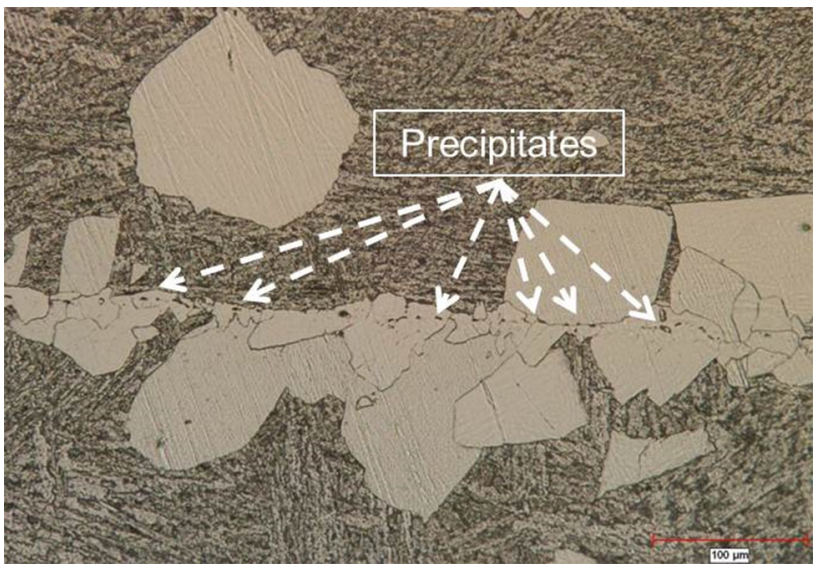

Fig. 5 Optical micrograph showing the presence of precipitates in pro-eutectoid ferrite phase and grain boundaries

phases such as sulfides, nitrides, carbides, and phosphorus could be formed (Fig. 6b). However, carbides such as $\mathrm{M}_{23} \mathrm{C}_{6}$ and $\mathrm{M}_{7} \mathrm{C}_{3}$ present the highest amounts as secondary phases. X-ray diffraction diagram revealed only the presence of body-centered cubic (BCC) phases, as illustrated in Fig. 7. Scanning electron microscopy observations of the fracture surface (Fig. 8a) confirmed the intergranular character of the crack propagation and the presence of precipitates. Furthermore, EDS chemical mappings, reported in Fig. 8b, shows the presence of chromium-rich precipitates scattered inside the thin intergranular cracks. Also, EDS chemical mappings around large cracks revealed continuous bands of chromium- and manganeserich precipitates on both sides of the crack as shown in Fig. 9b and c, respectively. 
Fig. 6 Evolution of the different phase fractions vs. temperature obtained, using Thermo-Calc ${ }^{\circledR}$ calculations, for the chemical composition of Table 1: (a) all the phases and (b) secondary phases
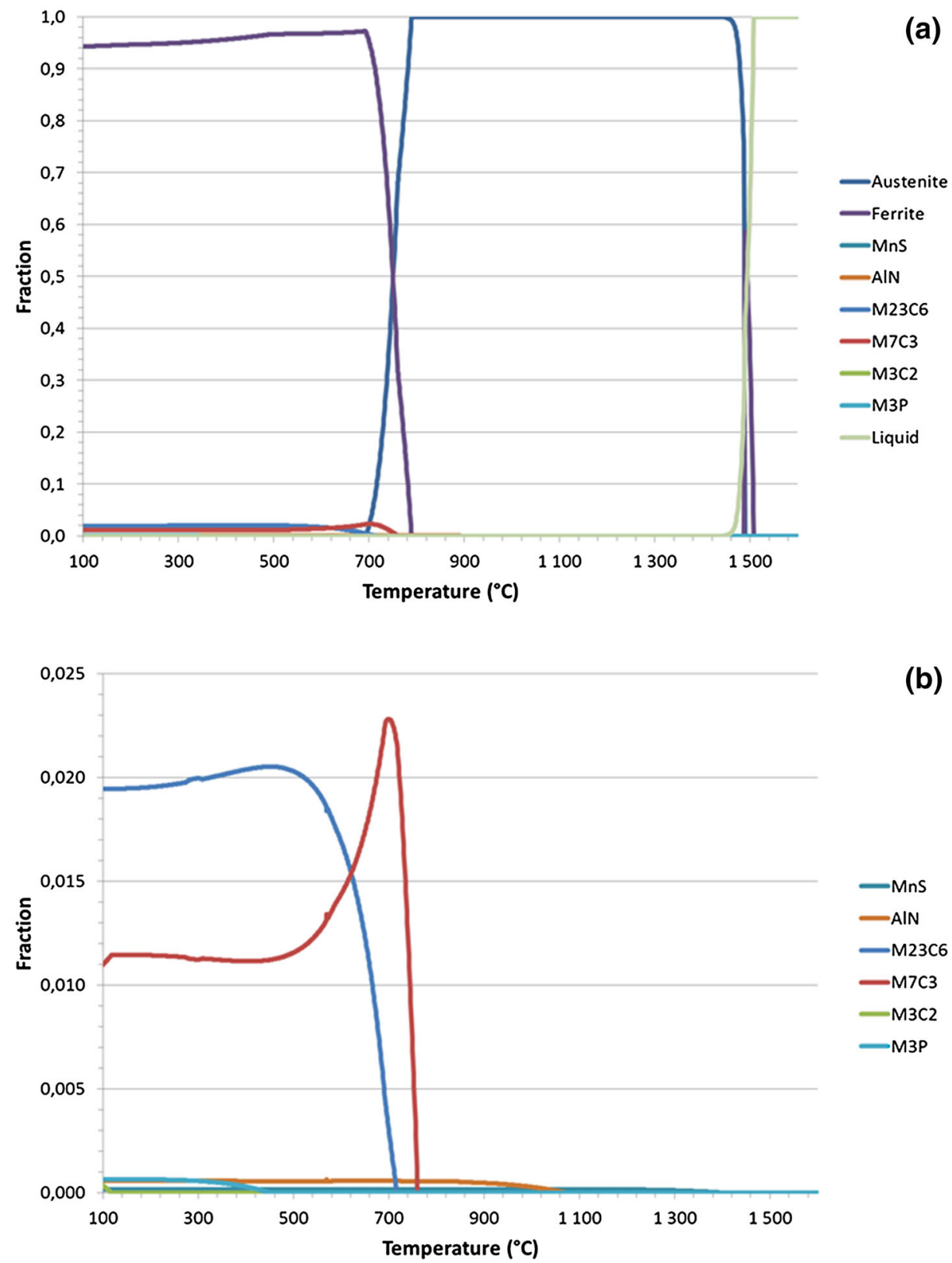

\section{Discussion}

The cracks were observed after the post-casting annealing heat treatment, which means that they could have been initiated and propagated during solidification or/and annealing processes. Therefore, all possible sources for cracking during these two processes must be systematically analyzed. Microhardness measurements of the white phase are in good agreement with those reported for alloyed ferrite phase [13, 14], indicating that the white phase is mostly composed of a rich ferritic phase. The presence of alloyed ferrite at prior austenite grain boundaries has been reported in AISI 4317 steel by previous authors [14]. It is well known that substitutional alloying elements such as chromium, nickel, and manganese have high solubility in ferrite: unlimited, 10 and $3 \mathrm{wt} \%$, respectively [15]. Such solid solution tends to increase the yield stress of ferrite and therefore the hardness compared to non-alloyed ferrite. Microhardness measurements of the more contrasted phase $(350 \pm 24 \mathrm{HV})$ correspond to that of a bainitic phase $[13,16]$, suggesting that the contrasted phase is bainite. These findings are in good agreement with $\mathrm{x}$-ray diffraction results which revealed only the presence of body-centered cubic (BCC) peaks.

The revealed ferrite phase corresponds to pro-eutectoid ferrite probably formed during the cooling of austenite. The 


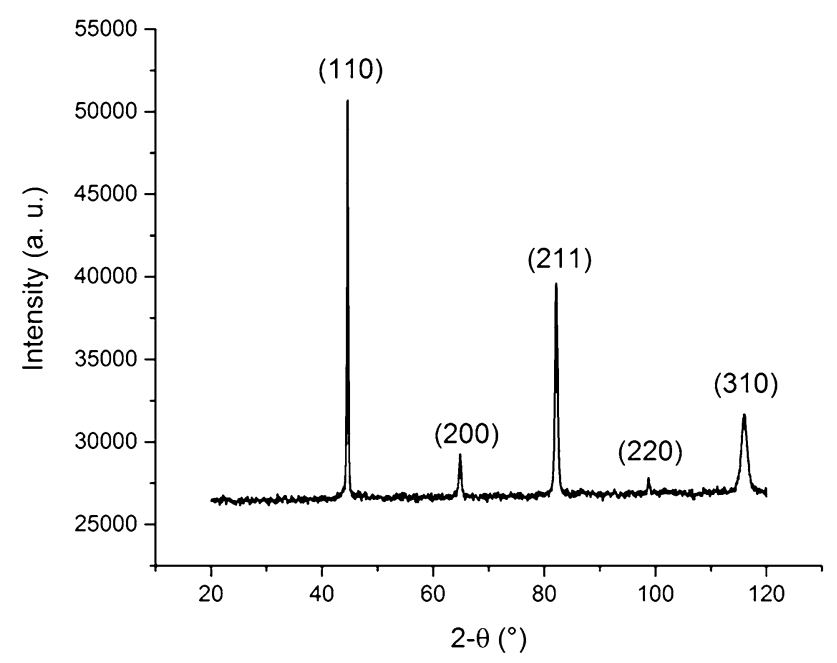

Fig. 7 X-ray diffraction spectra showing the presence of only the body-centered cubic (BCC) phase
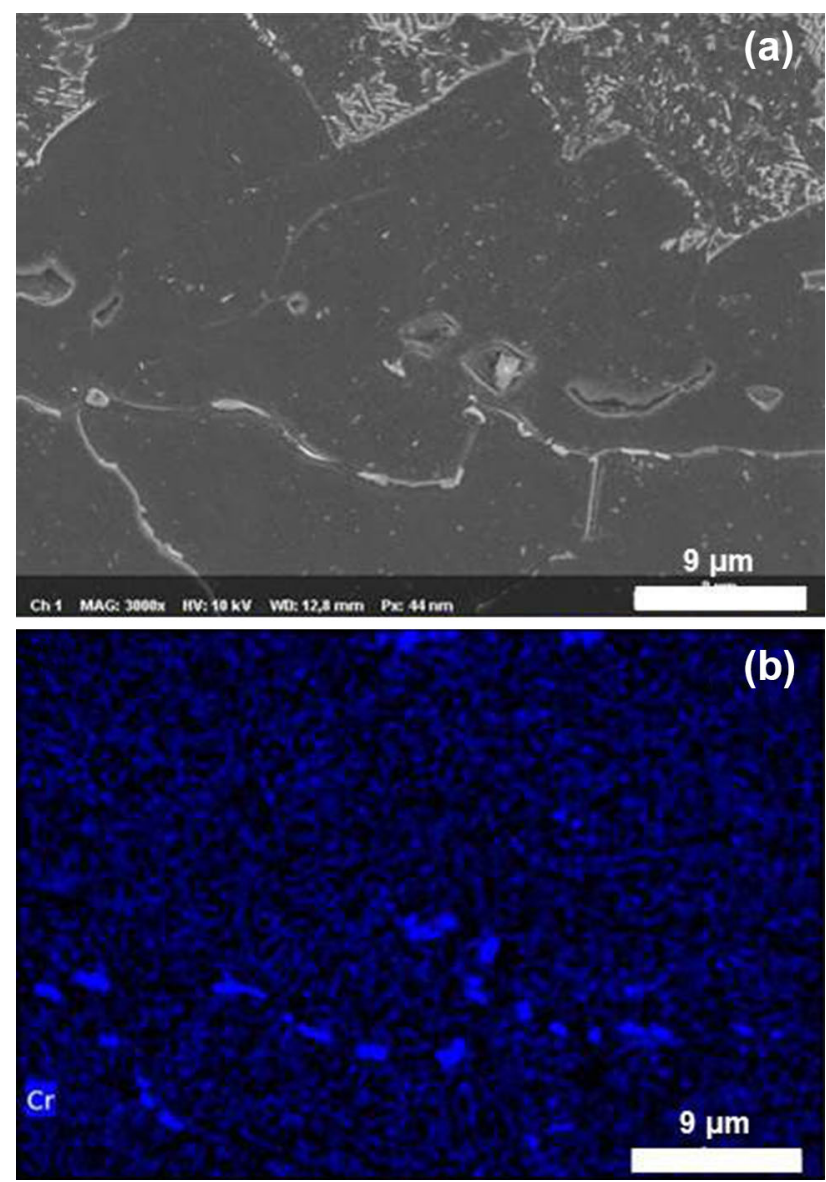

Fig. 8 EDS analyses for intergranular precipitates: (a) scanning electron microscopy micrograph and (b) chromium chemical mapping

important quantity of pro-eutectoid ferrite present close to the grain boundaries is probably due to its preferential nucleation in these zones [17]. Thomas et al. [1] analyzed cracks initiated during the early stages of reheating in a
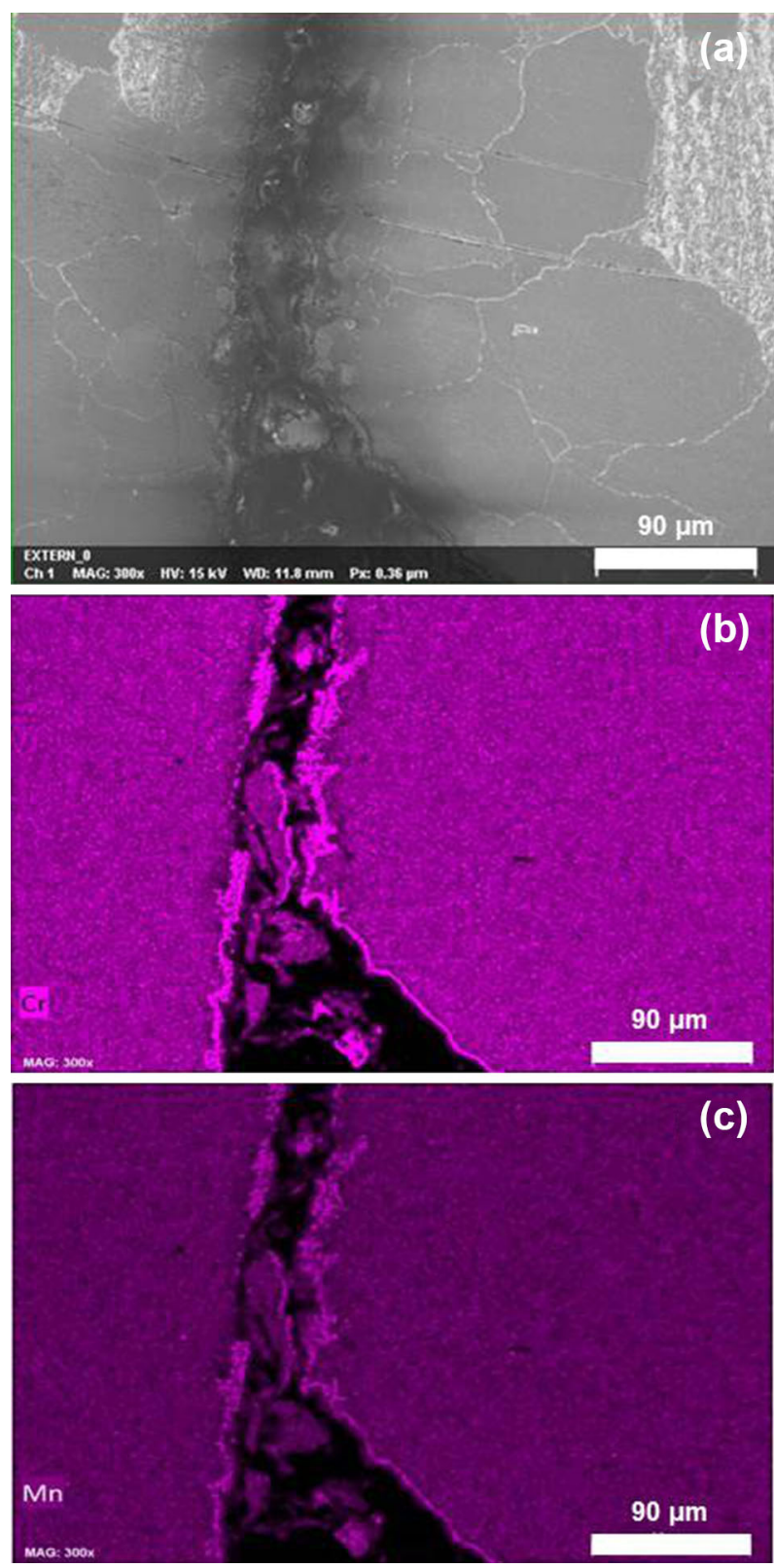

Fig. 9 EDS analyses for intergranular crack: (a) scanning electron microscopy micrograph, (b) chromium and (c) manganese chemical mappings

cast steel ingot. They found that, in general, cracks were located in regions where bands of pro-eutectoid ferrite were present within the ferritic-pearlitic structure. They also reported that these bands were precipitation sites for $(\mathrm{Fe}, \mathrm{Mn})$ silicates, $(\mathrm{Fe}, \mathrm{Mn})$ sulfides and $\mathrm{Fe}$ oxides.

Microstructural analyses reported in Figs. 8 and 9 did not reveal the presence of the most common secondary phases responsible for hot cracking such as manganese sulfides [4, 14] and aluminum nitrides [6]. In contrast, EDS analyses revealed chromium-rich precipitates in thin intergranular cracks. The possible formation of chromium 
carbides is in good agreement from a thermodynamic point of view as confirmed by Thermo-Calc ${ }^{\circledR}$ analysis. On the other hand, it is well known that the diffusivity of chromium and manganese is quite significant at high temperature in austenite as compared to nickel [18]. Therefore, the concomitant presence of chromium and manganese on both surfaces of large-size cracks (Fig. 9) could be attributed to the formation of chromium and manganese oxides due to intense oxygen diffusion through the cracks [3].

The majority of the observed cracks in this study were intergranular, indicating an important weakening of grain boundaries, similar to the embrittlement phenomenon due to aluminum nitride precipitates reported for low-alloy cast steels [19]. Therefore, the segregation of chromium and manganese at the grain boundaries could be one of the root causes of this weakening. Moreover, the detection of cracks in the columnar zone is a strong indicator of a high cooling rate during solidification. It is well known that the as-cast microstructure, depending on the temperature gradient, is composed of three zones: chill, columnar, and equiaxed [12], with the high cooling rate occurring in the columnar zone. Such high cooling rates are at the origin of important thermal stresses as reported by many researchers [9, 10].Therefore, the combination of weakened grain boundaries and a fast cooling rate could be at the origin of crack initiation. In addition to the above factors, the contribution from austenite to ferrite transformation in the development of tensile stresses and therefore crack initiation has to be considered [1]. However, the degree of such stresses is very dependent on the rate of cooling and reheating undergone by the ingot.

\section{Conclusions}

Experimental characterizations were carried out to understand the root causes of cracking in an as-cast and annealed high-strength low-alloy steel ingot. The mechanisms of crack initiation have been identified as the result of high cooling rates combined with weakened grain boundaries due to solute segregation. The obtained results also revealed the high sensitivity of the examined steel cooling rate during solidification. Therefore, this rate should be controlled with higher accuracy than the existing practices in order to avoid cracking.

\section{References}

1. B.G. Thomas, I.V. Samarasekera, J.K. Brimacombe, Investigation of panel crack formation in steel ingots: part II. Off-corner panel cracks. Metall. Trans. B 19B, 289-301 (1988)
2. A. Kermanpur, M. Eskandari, H. Purmohamad, M.A. Soltani, R. Shateri, Influence of mould design on the solidification of heavy forging ingots of low alloy steels by numerical simulation. Mater. Des. (2010). https://doi.org/10.1016/j.matdes.2009.09.045

3. M. Bitterlin, A. Loucif, N. Charbonnier, M. Jahazi, L.-P. Lapierre-Boire, J.-B. Morin, Cracking mechanisms in large size ingots of high nickel content low alloyed steel. Eng. Fail. Anal. (2016). https://doi.org/10.1016/j.engfailanal.2016.05.027

4. G. Das, S. Ghosh, S.G. Chowdhury, S. Ghosh, S. Das, D.K. Bhattacharaya, Investigation of sub-surface cracks in continuous cast billets. Eng. Fail. Anal. (2003). https://doi.org/10.1016/ S1350-6307(02)00037-7

5. B. Santillana, R. Boom, D. Eskin, H. Mizukami, M. Hanao, M. Kawamoto, High-temperature mechanical behavior and fracture analysis of a low-carbon steel related to cracking. Metall. Mater. Trans. A (2012). https://doi.org/10.1007/s11661-012-1331-1

6. J. Maciejewski, C. Regulski, A case of aluminum nitride embrittlement of heavy wall cast steel. J. Fail. Anal. Prev. (2017). https://doi.org/10.1007/s11668-017-0360-x

7. S. Harada, S. Tanaka, H. Misumi, S. Mizoguchi, H. Horiguchi, A formation mechanism of transverse cracks on CC slab surface. ISIJ Int. 30, 310-316 (1990)

8. J. Campbell, Castings: The New Metallurgy of Cast Metals, 2nd edn. (Butterworth-Heinemann, Oxford, 2003)

9. K. Tashiro, S. Watanabe, I. Kitagawa, I. Tamura, Influence of mould design on the solidification and soundness of heavy forging ingots. Trans. ISIJ 23, 312-321 (1983)

10. Y. Yang, W. Luo, M. Chen, G. Shao, Simulation analysis of thermal stress during casting process of large-sized alloy steel ingot. Front. Mater. Sci. China (2009). https://doi.org/10.1007/ s11706-009-0049-5

11. ASTM E384-16, Standard Test Method for Microindentation Hardness of Materials (ASTM International, West Conshohocken, PA, 2016)

12. G. Krauss, Solidification, segregation, and banding in carbon and alloy steels. Metall. Mater. Trans. B 34B, 781-792 (2003)

13. B.L. Bramfitt, Structure/property relationships in irons and steels, in Metals Handbook Desk Edition, 2nd edn., ed. by J.R. Davis (ASM International, Materials Park, 1998), pp. 153-173

14. S. Henschel, J. Gleinig, T. Lippmann, S. Dudczig, C.G. Aneziris, H. Biermann, L. Krüger, A. Weidner, Effect of crucible material for ingot casting on detrimental non-metallic inclusions and the resulting mechanical properties of 18CrNiMo7-6 steel. Adv. Eng. Mater. (2017). https://doi.org/10.1002/adem.201700199

15. C.P. Sharma, Alloy Steels, Engineering Materials: Properties and Applications of Metals and Alloys (PHI Learning Pvt. Ltd, Delhi, 2003)

16. K. Abbaszadeh, H. Saghafian, S. Kheirandish, Effect of bainite morphology on mechanical properties of the mixed bainitemartensite microstructure in D6AC steel. J. Mater. Sci. Technol. 28(4), 336-342 (2012)

17. F.C. Campbell, The Iron-Carbon System: Elements of Metallurgy and Engineering Alloys (ASM International, Materials Park, 2008), pp. 153-176. https://doi.org/10.1361/emea2008p153

18. W.F. Gale, T.C. Totemeier, Smithells Metals Reference Book, 8th edn. (Butterworth-Heinemann, Oxford, 2003)

19. C. Li, Z. Guangying, Intergranular fracture of low-alloy cast steel. Mater. Charact. 36, 65-72 (1996) 